\title{
Temáticas Recentes dos Centros de Investigação Sociológica em Portugal Contributos Breves a partir de uma Pesquisa Exploratória
}

Alda Gonçalves ${ }^{1}$

\begin{abstract}
$\mathrm{R}$ mo: Este ensaio permite relembrar alguns dos aspectos relevantes da história da Sociologia para a compreensão dos seus desenvolvimentos mais recentes. Foi possível traçar uma panorâmica sobre os principais centros de investigação produtores de conhecimento sociológico, analisando algumas dimensões que permitem contribuir para uma sociografia disciplinar que se baseou em dimensões como a territorialização, com um centramento muito forte em Lisboa, nas principais temáticas de investigação, assim como numa breve análise das Revistas de difusão do conhecimento e da cultura científica, analisando a sua evolução e expansão no tempo, bem como a regularidade da sua publicação. Estas constituem apenas duas das faces institucionais da investigação sociológica em Portugal.

No caso dos Centros de Investigação, observa-se uma expansão, que contribui quer para a visibilidade pública, quer para a institucionalização disciplinar, mais acentuada no decurso dos anos 80 e 90, enquanto as Revistas registaram maior expansão em anos mais recentes.

Constituíram ainda objecto de análise os principais domínios de produção sociológica dos Centros de Investigação, categorizando-se as linhas de pesquisa actuais, de acordo com alguns domínios de produção sociológica tendo-se tornado perceptível que cada Centro possui mais do que uma linha de pesquisa (uma média de 4, $5 \%$ ). Assinale-se que a quantidade e diversidade de linhas de investigação observadas demonstram, simultaneamente uma abrangência de estudos sobre a complexidade da realidade social e uma conexão com os problemas sociais emergentes.
\end{abstract}

Palavras-chave: Centros de Investigação; Revistas de difusão científica; Produção Sociológica.

\section{Introdução}

Nos últimos anos, têm ocorrido intensas transformações sociais, demográficas, económicas, institucionais, políticas, comunicacionais, culturais e também científicas fundamentais quer em Portugal, quer na Europa, contudo, a par continua a verificar-se um aprofundamento das desigualdades e a emergência de novos problemas sociais aos quais a evolução da investigação sociológica portuguesa não tem sido alheia.

A sua capacidade teórica e reflexiva e os instrumentos técnicos e metodológicos de que dispõe e constrói para responder às solicitações societais, quer no âmbito de investigações aplicadas, quer no da investigação fundamental, constituem mais valias inquestionáveis na decifração, compreensão e descrição, bem como na análise, na avaliação e nos contributos para decisões mais informadas.

O objecto de estudo do presente ensaio é, justamente, a investigação sociológica portuguesa, mas a sua amplitude tornou necessária uma focalização do olhar sociológico num objecto um pouco mais restrito. Assim tornou-se objecto de análise duas das faces públicas institucionais de enquadramento e visibilidade da investigação sociológica em Portugal: uma panorâmica dos Centros de Investigação existentes em território nacional e as suas principais linhas de pesquisa, categorizadas por abordagens temáticas, bem como as Revistas que alguns desses Centros possuem, contabilizando-se a produção observada na fase mais recente de desenvolvimento e consolidação disciplinar (2000 - 2007).

\footnotetext{
1 Técnica Superior do Instituto da Segurança Social, IP. Contacto: Alda.M.Goncalves@seg-social.pt
} 
$\mathrm{Na}$ realidade, este pequeno ensaio, teoricamente informado, nomeadamente pelos contributos inspiradores de José Madureira Pinto (2004, 2007), Fernando Luís Machado (1988, 1996, 2007) e António Teixeira Fernandes (1996), não possui pretensões de exaustividade ou de representatividade, já que os Centros de investigação (25) e as respectivas revistas (16) não são os únicos instrumentos de produção científica, institucionalização e visibilidade disciplinar, em Portugal, mas possuem certamente uma importância fulcral. Do período temporal em análise, poder-se-ia dizer que é muito curto, não fosse o facto de permitir evidenciar de forma clara o impulso que, na viragem do século, demonstra a consolidação da sociologia, a avaliar pelo impressionante número de Revistas científicas publicadas nos anos em referência, pois detectaram-se 16 revistas, que publicaram em conjunto 181 números.

Inquestionável, pois, a relevância da Sociologia torna-se visível na resposta aos problemas sociais, que transforma em fenómenos sociológicos para os questionar e lhes definir contornos e causalidades; nos contributos que presta às instituições e às políticas públicas, assim como nas colaborações com outras disciplinas sociais. Outro contributo importante, embora menos visível, é o que a "sociologia dá para aumentar a reflexividade da sociedade portuguesa, para o autoconhecimento que constitui condição de cidadania. Por múltiplas vias (...) os instrumentos conceptuais que a disciplina cumulativamente foi forjando e os resultados da sua aplicação, vão sendo transferidos para camadas alargadas da nossa sociedade, permitindo escolhas mais informadas na configuração do nosso futuro colectivo" (Almeida, 2005: 2).

Mas esta relevância disciplinar só se torna reconhecida quando é dada a conhecer ao exterior, quando é tornada pública e, neste contexto, não é possível esquecer os primeiros esforços e os contributos decisivos de Adérito Sedas Nunes para tal visibilidade pública e institucionalização dos primeiros estudos sociais, verdadeiros percursores da investigação sociológica, ainda em plena época salazarista.

J. Madureira Pinto $(2004,2007)$ considera algumas fases importantes na formação e desenvolvimento da sociologia em Portugal, em consonância com a evolução das conjunturas políticas, sociais e económicas, como: primórdios (a partir do último quartel do século XIX), interregno (durante o
Estado Novo) e um novo fôlego (a partir de 1960), consideradas pelo autor como fases de "acumulação primitiva" de recursos cognitivos e organizacionais da disciplina, seguidas de uma fase de consolidação com a Revolução de Abril de 1974, que marcou a viragem e a institucionalização disciplinar. Os contributos de A. Teixeira Fernandes (1996) denotam também esta linha de abordagem.

Os primórdios reportam-se ao século XIX, tomando como expoente máximo o trabalho de Teófilo Braga que foi influenciado por Augusto Comte e Spencer, aderindo ao positivismo e cuja influência se nota nomeadamente na sua obra Systema de Sociologia, de 1884. Assim, "a Sociologia é entendida na sua acepção de filosofia positiva, de harmonia com a perspectiva comteana e, do ponto de vista metodológico, privilegia o todo na explicação dos fenómenos particulares, com uma clara orientação sistémica" (Fernandes, 1996).

Observou-se ainda uma primeira tentativa de institucionalização da disciplina, na Faculdade de Direito da Universidade de Coimbra (1901) já com referências teóricas a Durkheim, Simmel, Tarde, Tonies e os fundadores da Sociologia norte-americana, até ser substituída pela Economia Política, em 1911 (Cf. Pinto, 2007).

A designada fase de interregno, pauta-se essencialmente pela estagnação já que não existia ainda uma capacidade de institucionalização nem uma comunidade intelectual estabilizada e o golpe militar de 1926 constitui um factor decisivo que fará com que, durante quase cinco décadas de ditadura, a reflexão mais sociológica seja entendida como ameaça à segurança do Estado. Por outro lado, também não se verificava uma procura deste tipo de conhecimentos, nomeadamente pelo isolamento cultural de variados sectores da população e alguma confusão linguística entre sociologia e socialismo.

Contudo, alguns factores económicos e sociais que ocorrem na década de 60, como uma certa abertura económica ao exterior, a emigração, a proletarização de um grande contingente de camponeses, devido à intensificação dos processos de urbanização e a difusão de quadros de pensamento de cariz "desenvolvimentista", são responsáveis pela criação de condições para “(...) um pensamento sistemático e academicamente enquadrado sobre o social." (Pinto, 2004: 14) Verificando-se que, posteriormente serão sectores próximos do poder 
a solicitar contributos de tipo sociológico, para fundamentar, de algum modo, a “(...) racionalização da acção política e, em particular, de planeamento da economia" (Pinto, 2004: 14).

Assim se observa um novo fôlego, com "os primeiros esforços sistemáticos para recolocar a disciplina no mapa das Ciências Sociais, no que respeita à investigação e ao ensino, o que aconteceu sobretudo ao longo dos anos 60, devem-se, como é sabido, a Adérito Sedas Nunes. Só Abril de 74, contudo, permitiu finalmente trazer à luz do dia a possibilidade real de pesquisa e a desejada institucionalização universitária" (Almeida, 2005: 1)².

Em 1962, “o Gabinete de Investigações Sociais estava, por fim, criado, e com ele fundada estava a Análise Social, em 1963. (Nunes, 2000: 341) Abria-se assim, um novo espaço no panorama intelectual português, “(...) o espaço do estudo e da reflexão sobre as realidades sociais." (Nunes, 2000: 341) Espaço este que não tem cessado de crescer e de se expandir.

O GIS foi inicialmente constituído por um grupo de jovens estudiosos dos problemas sociais, quase todos economistas e com fortes ligações ao movimento católico.

Adérito Sedas Nunes foi uma figura decisiva na história da investigação social e precursora da sociologia portuguesa, revelando uma importante intuição sociológica, nomeadamente quanto ao papel e ao estudo das classes sociais ${ }^{3}$ na interpretação de processos de mudanças socioeconómicas e culturais em curso.

De acordo com este autor, "a partir dos últimos anos 70 e dos primeiros 80, os investigadores sociais foram confrontados com os requisitos da carreira docente universitária, restaurada e reformada, e da carreira de investigação científica, pela primeira vez regulada." (Nunes, 2000: 351)

Estes impulsos foram decisivos para que a investigação sociológica em Portugal se pudesse desenvolver, já em período democrático, a partir de Abril de 1974, com a designada institucionalização disciplinar, em fase de consolidação, tendo-se assistido à primeira Licenciatura em Sociologia, no
ISCTE logo nesse ano, enquanto o $1 .^{\circ}$ Doutoramento em Sociologia realizado em Portugal só foi possível em 1983 e também no ISCTE.

$\mathrm{Na}$ realidade, o final da década de 80 e decurso da década de 90 foram os tempos de maior desenvolvimento e afirmação da Sociologia, recorrendo à diversificação das formas de institucionalização e visibilidade pública do trabalho desenvolvido.

Podem considerar-se algumas características desta fase de consolidação e desenvolvimento como: uma abertura significativa aos quadros teóricos provenientes dos países centrais; um contexto editorial em alteração, através de publicação de revistas científicas e de algumas obras fundamentais; os encontros científicos, o aumento das Licenciaturas, inclusive no ensino privado e em consequência o aumento do n. ${ }^{\circ}$ de alunos - de acordo com J. Madureira Pinto (2007), no ano lectivo 2003/04, havia registo de cerca de 4000; os Centros de investigação que surgem muito ligados às Universidades ${ }^{4}$, vão permitindo o aparecimento e desenvolvimento de estudos sobre a realidade social portuguesa, inicialmente com enquadramentos institucionais precários.

Dela faz ainda parte uma relevante "inventiva metodológica", numa articulação profícua entre reflexão teórica e pesquisa empírica e a este surgimento tardio da disciplina em Portugal atribuem-se virtualidades, nomeadamente a da plena utilização da diversidade de instrumentos técnicos à disposição, desde que adequada ao objecto específico em estudo.

Esta rápida síntese sobre alguns dos elementos essenciais do desenvolvimento da sociologia em Portugal enquadra a breve pesquisa efectuada neste ensaio, que baseando-se numa pesquisa de carácter exploratório, procura incidir, sobretudo, em duas das características referidas como contributos para a consolidação disciplinar - os Centros produtores de pesquisa sociológica e, muitas vezes, associadas a eles, as Revistas científicas que permitem a sua difusão.

Esta pesquisa foi efectuada através da Internet entre 27.Dez.07 e 10.Jan.08, sobre os Centros de Investigação sociológica existentes em Portugal, a

\footnotetext{
2 Sessão comemorativa dos 20 anos da APS, 08.Setembro.2005.

${ }^{3}$ Há diversos exemplos de textos de lições e documentos pedagógicos, por si organizados sobre esta problemática. Veja-se a título de exemplo, nomeadamente Elementos de Teoria e Análise da Estratificação e das Classes Sociais, Ed. ISCTE.

${ }^{4}$ Ver Quadro 1. Tipologia dos Centros de Investigação Sociológica, em Portugal, na pág. 117.
} 
sua distribuição pelo território, quais as linhas temáticas de investigação privilegiadas e se dispõem ou não de Revista científica, como instrumento que permite dar maior visibilidade à investigação realizada. Foi seguidamente efectuada uma análise de conteúdo temática às linhas de investigação propostas pelos Centros, de acordo com uma das categorizações possíveis. Efectuou-se ainda uma focalização nas abordagens sobre a pobreza e a exclusão social, dando conta de uma significativa transversalidade face a várias temáticas, pela reconhecida multidimensionalidade dos fenómenos em causa.

Esta pesquisa permitiu, justamente, detectar uma dinâmica crescente em termos do número de Centros de Investigação no domínio da Sociologia e uma enorme diversidade de temáticas/problemáticas abordadas, muitas vezes consonantes com problemas sociais emergentes. Foram analisados indicadores como o n. ${ }^{\circ}$ de Centros, sua evolução temporal, distribuição territorial e linhas de pesquisa, assim como o n. ${ }^{\circ}$ de revistas por Centro, a sua evolução temporal, distribuição territorial e designação, assim como os n. ${ }^{\text {os }}$ publicados na fase mais recente de desenvolvimento da sociologia, em Portugal.

\section{Contributos para a Consolidação e Expansão Recente da Investigação Sociológica}

\section{Os Centros de Investigação}

A pesquisa efectuada permitiu observar uma grande variedade de temáticas e de perspectivas de abordagem relativamente aos domínios de produção sociológica recente em Portugal, mas também uma evolução em termos de crescimento do número de centros que tem, de certo modo, acompanhado as mudanças societais às quais se tem assistido em Portugal, nomeadamente após a integração na União Europeia.

Observa-se grande criatividade ancorada numa reflexividade demonstrativa de uma maior maturidade da disciplina, capaz de responder às mudanças e às complexidades actuais, verificando-se também vários domínios "especializados" em cruzamento e uma crescente heterogeneidade problemática que, muitas vezes, dificulta categorizações mais rigorosas.

Esta dinâmica visível num total de, pelo menos, vinte e cinco Centros de investigação detectados no País encontra-se estreitamente ligada ao meio académico e universitário público, com uma representatividade dominante $(84 \%)^{5}$. Três dos Centros (12\%) registam-se como Associações Particulares sem fins Lucrativos, considerando que uma é de carácter profissional, a APSIOT (Associação Portuguesa de Profissionais em Sociologia Industrial, das Organizações e do Trabalho) ${ }^{6}$, outra afirma-se pela especificidade problemática - estudos sobre as mulheres, a Associação Portuguesa de Estudos sobre as Mulheres ${ }^{7}$, enquanto outra se assume como um Centro de estudos com especial enfoque na investigação aplicada, o CESIS (Centro de Estudos para a Intervenção Social) ${ }^{8}$, por último, um Centro que se insere no Laboratório Nacional de Engenharia Civil (NESO) ${ }^{9}$, funcionando numa perspectiva interdisciplinar. Observa-se assim um domínio muito significativo dos espaços produtores de investigação sociológica em meio universitário público.

\footnotetext{
${ }^{5}$ Um destes Centros não funciona como produtor de actividades de investigação. Trata-se do Gabinete de Investigação e Acção Social criado em 1965 por jesuítas, no ex-Instituto Superior Económico e Social de Évora, cujas actividades lectivas foram suspensas após 25.Abril.1974. O Instituto/ /Centro funciona hoje como Biblioteca e como entidade promotora da Revista Economia e Sociologia, publicada com financiamento da Fundação Eugénio de Almeida. Os principais impulsionadores da Revista são sobretudo Professores da Universidade de Évora, factor que determinou a opção assumida. Outro é uma Unidade (UNICS/ ISCTE) que se optou por considerar neste tipo, devido ao facto de se situar em contexto académico e de se constituir como elemento agregador de vários Centros, com diversidade de domínios de produção do saber no contexto das ciências sociais, nomeadamente a Sociologia. Por fim, considerou-se também o Departamento de Sociologia do ISCTE, uma vez que por ele passam por vezes alguns projectos e, sobretudo, porque uma das Revistas científicas possui a sua chancela.

6 A APSIOT assume-se como uma associação de carácter cultural, sem fins lucrativos e afirma possuir como objectivo promover o conhecimento científico e técnico para o desenvolvimento da actividade no domínio da Sociologia Industrial das Organizações e do Trabalho, e contribuir para o conhecimento, aperfeiçoamento, progresso, divulgação e deontologia da profissão.

7 A Associação Portuguesa de Estudos sobre as Mulheres (APEM) é uma associação de carácter científico, sem fins lucrativos, que visa apoiar, promover e dinamizar os Estudos sobre as Mulheres em todas as áreas do saber, nomeadamente ciências sociais e, portanto, também Sociologia.

8 Enquadra-se aqui o Centro de Estudos para a Intervenção Social (CESIS), que é uma associação sem fins lucrativos e assume promover formas de trabalho interdisciplinar, contando com a colaboração regular de investigadores/as, bem como de outros/as técnicos/as de diferentes áreas das ciências sociais: sociologia, economia, psicologia, antropologia, serviço social.

9 Trata-se do Núcleo de Ecologia Social (NESO), do Laboratório de Engenharia Civil.
} 


\section{Quadro 1. Tipologia de Centros de Investigação Sociológica, em Portugal}

\begin{tabular}{lcc|}
\hline Tipos de Centros de Investigação & $\mathbf{N .}^{\mathbf{o}}$ & $\%$ \\
\hline $\begin{array}{l}\text { Centros de Investigação } \\
\text { Sociológica em contexto }\end{array}$ & & \\
$\begin{array}{l}\text { Universitário } \\
\text { Associações particulares }\end{array}$ & 21 & 84,0 \\
$\begin{array}{l}\text { sem fins lucrativos } \\
\text { Centros de Investigação } \\
\text { Sociológica de Entidades }\end{array}$ & 3 & 12,0 \\
Públicas & & \\
\hline \multicolumn{1}{c}{ Total } & 1 & 40 \\
\hline
\end{tabular}

Fonte: Pesquisa efectuada através da Internet, entre 26.Dez.07 e 10.Jan.08.

Verifica-se também uma crescente internacionalização dos Centros de Investigação referidos, quer por via da participação em projectos, destacando perspectivas comparadas entre países, sobretudo europeus, e/ou pela participação em redes de investigação internacionais.

Boa parte dos Centros de investigação (40\%), excepto o GIS (1962) que esteve na base de constituição do ICS (1982) e do Gabinete de Investigação e Acção Social (Évora, 1965), que hoje resume a sua actividade a uma Biblioteca e à produção de uma revista científica, surgiram nos anos 80, fase designada por José Madureira Pinto (2007: 77) de "consolidação", contribuindo efectivamente para a institucionalização e reconhecimento da disciplina e corporizando justamente uma das faces públicas do trabalho sociológico, não sendo aqui objecto de análise outras formas ou instrumentos também relevantes desta visibilidade, como, p. e., Congressos e Encontros Científicos que vão sendo realizados inclusivamente pelos Centros em análise. Verificou-se a continuação da expansão no decurso da década de 90 (40\%) e registou-se, em seguida, menor intensidade desse crescimento até ao momento presente $(8 \%)$.

\section{Gráfico 1. Crescimento dos Centros de Investigação}

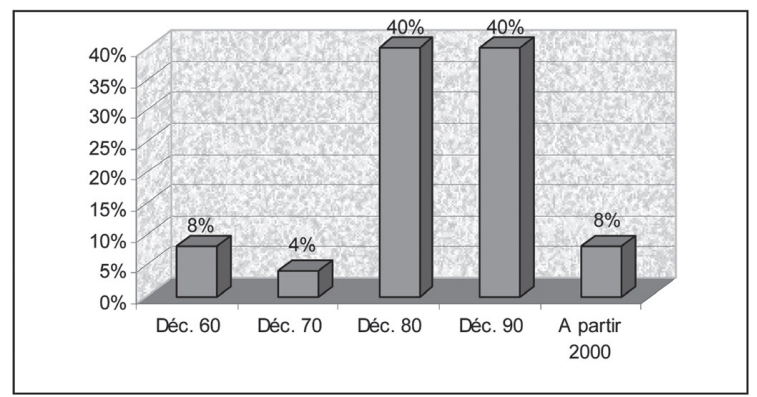

De resto, pode pressupor-se uma estreita relação entre esta expansão registada nos anos 80 e 90, com uma conjugação de factores que aliaram exigências de pertença à UE e necessidades de resposta face a instrumentos estratégicos de planeamento, investigação, intervenção, acompanhamento e avaliação, em diversos níveis (nacional, regional e local). Vários foram os(as) sociólogos(as) que iniciaram e validaram as suas experiências profissionais em Programas e projectos assim surgidos, como, por exemplo, no III $^{\circ}$ Programa Europeu de Combate à Pobreza, conhecido por Pobreza 3 (em 1989), no início dos anos 90, assim como na concepção, implementação e avaliação de diversos Projectos de Luta contra a Pobreza nacionais, que se seguiram.

Em finais dos anos 90, início de 2000, a própria Administração Pública, central, regional e local, convocou os saberes sociológicos na concepção, definição, acompanhamento e avaliação de políticas públicas. Um dos exemplos paradigmáticos ao nível da Administração central foi o do ex-Instituto para o Desenvolvimento Social (IDS) ${ }^{10}$ e, ao nível local, o das Câmaras Municipais.

Ao analisar a territorialização dos centros de investigação, como se pôde observar na fig. 1, ela é demonstrativa da grande concentração em Lisboa, basicamente com uma ancoragem dos centros em análise repartidas por 5 Universidades/ Institutos públicos, nomeadamente a FCSH-UNL (7), o ISCTE (5), FL (1), a FC-UL (1) e o ISEG (1) ${ }^{11}$, em

\footnotetext{
${ }^{10}$ O Instituto para o Desenvolvimento Social foi criado pelo Decreto-Lei $.^{\circ} 115 / 98$, de 4 de Maio, tendo como missão e objectivos dinamizar e gerir as políticas de desenvolvimento social e de luta contra a pobreza e a exclusão social, bem como apoiar o trabalho em parceria. Foi-lhe cometida a implementação de políticas públicas como o RMG, o Programa Rede Social e a Coordenação do primeiro Plano Nacional de Acção para a Inclusão 2001-2003 (cuja necessidade de elaboração tinha sido assumida na Cimeira de Lisboa, em 2000, pelos Chefes dos Estados Membros da UE e cujos objectivos comuns foram definidos no mesmo ano, na Cimeira de Nice), áreas que permitiram o aumento da tx. de emprego de sociólogos. O IDS foi extinto, por decisão do próprio Governo que o criou e as suas funções e funcionários foram integrados no Instituto da Segurança Social, em 2003, na sequência da mudança de governo.

${ }^{11}$ Cf. Quadro síntese em anexo.
} 
Associações particulares sem fins lucrativos (3) e Centros de Investigação Sociológica de Entidades Públicas; observando-se em seguida uma distribuição territorial que privilegia o litoral ao Centro e a Norte, englobando a FEUC, em Coimbra (1), o Inst. de Sociologia do Porto (1) e o CICS da Universidade do Minho, em Braga (1) em detrimento Interior, com a UBI, Covilhã (1) e do Sul, com Évora $\left(2^{12}\right)$. Relativamente às regiões Autónomas, detectou-se apenas um Centro de Investigação, nos Açores. Esta distribuição territorial marca, sem dúvida, o que se investiga (linhas de investigação e os objectos de estudo) o onde se investiga (os territórios).

De resto, esta tendência de grande centramento em Lisboa, foi também detectada por Pedro Abrantes (2004), embora numa análise do caso específico da produção sociológica na área da Educação, quando se refere às instituições e protagonistas das comunicações efectuadas nos principais encontros da APS e SPCE (entre 1985 e 2000).

\section{Fig. 1. Territorialização dos Centros de Investigação Sociológica, em Portugal}

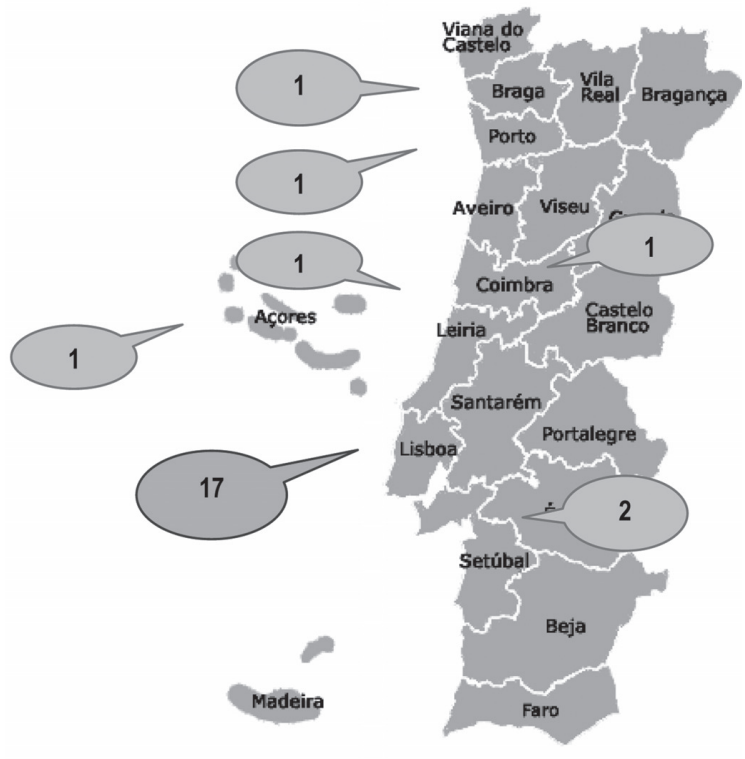

As Revistas Científicas

As Revistas científicas criadas no contexto destes Centros constituem outra das faces públicas da investigação sociológica portuguesa, demonstrando a maioria, uma regularidade de publicações muito significativa, reveladora de uma dupla condição: de uma produção/investigação sociológica intensas e de um público que procura contributos científicos, conhecimentos e reflexividade experimentada e especializada face à complexidade da sociedade actual, ou para sua legibilidade. Constituem também expressão e contributo para a divulgação da cultura científica, em Portugal.

Constata-se desde logo um predomínio das Revistas ligadas aos Centros existentes em meio Universitário $(87,5 \%)$ e apenas $12,5 \%$ ancoradas em Associações, uma na APSIOT, especificamente vocacionada para a profissionalização em contexto organizacional e outra na APM, voltada para os estudos sobre as mulheres efectuados em áreas diversas das ciências sociais (desde a sociologia, ao direito, à saúde, à economia, entre outras). Neste contexto, o padrão de territorialização das revistas, é semelhante ao evidenciado para os centros de investigação.

\section{Quadro 2. Ancoragem de Revistas Científicas de Difusão da Investigação Sociológica Portuguesa}

\begin{tabular}{lccc}
\multicolumn{1}{c}{$\begin{array}{c}\text { Tipos de Ancoragem das Revistas } \\
\text { Científicas }\end{array}$} & $\mathbf{N .}^{{ }^{\circ}}$ & $\%$ \\
\hline & & \\
Revistas em contexto Universitário & 14 & 87,5 \\
Revistas em Associações & 2 & 12,5 \\
\hline & Total & 16 & $100 \%$
\end{tabular}

Fonte: Pesquisa efectuada através da Internet, entre 26.Dez.07 e 10.Jan.08.

Relativamente às designações das revistas cientificas de difusão da produção sociológica portuguesa, é interessante constatar que das 16 detectadas (embora duas já não sejam publicadas), $31,25 \%$ (5) possuem referência à Sociologia na própria designação, como a Sociologia Problemas e Práticas ou a Fórum Sociológico, 31,25\% (5), fazem uma referência às ciências sociais no nome, como a Análise Social ou a Revista Crítica de Ciências Sociais, demonstrando alargamento do seu campo de divulgação, enquanto $37,5 \%$ (6) restringem o seu âmbito de publicação a domínios de produção sociológica especializados como, por exemplo, a revista Organizações e Trabalho ou a revista Cidades. Comunidades e Territórios. 
Foi também possível constatar que 37,5\% das revistas surgiram a partir de $2000,25 \%$ na década de 80, 18,8\% nos anos 90, 12,5\% antes da institucionalização da disciplina (na década de 60) e apenas 6,2\% em 1975. Como se pode constatar este instrumento de divulgação científica possui hoje uma amplitude e expressividade maior.

\section{Gráfico 2. Crescimento das Revistas Científicas}

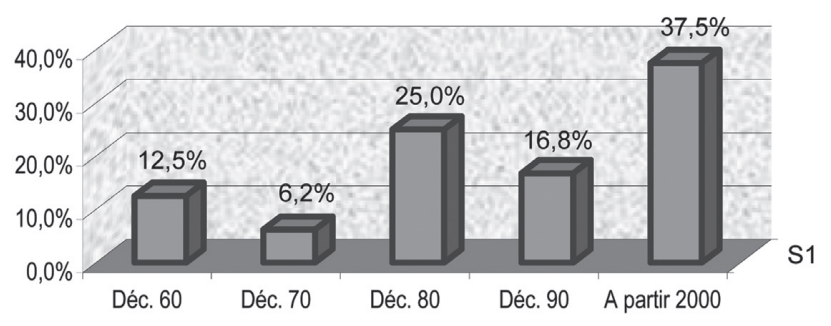

Importa ainda assinalar que das 16 Revistas, duas já não são publicadas, contribuindo no entanto para o património do conhecimento adquirido, a Revista Arquipélago e a Sociedade e Cultura Cadernos do Noroeste, tendo esta última sido substituída pela Configurações, Revista de Sociologia.

Por último, quanto aos quadros teóricos de referência e às metodologias utilizadas ${ }^{13}$, quer no âmbito dos Centros, quer no das Revistas onde a extensividade temática/problemática e de especialização disciplinar é ainda mais abrangente, embora não tendo sido objecto de análise aprofundada indiciam a identificação de algumas das tendências que José Madureira Pinto refere (2007). Isto é, tais tendências reportam-se fundamentalmente a propostas de síntese teórica de autores de referência internacional como Pierre Bourdieu e Antthony
Giddens, à designada "teoria crítica" patente, por exemplo, em Boaventura de Sousa Santos, mas também a perspectivas "simbólico-construtivistas" e instrumentos metodológicos assentes em "procedimentos de observação (...) das tradições estrutural-positivas e fenomenológicas, com efectiva subversão de rotinas e fronteiras presentes com frequência nos habitus profissionais dos sociólogos e antropólogos das comunidades "centrais" - nomeadamente as que aí foram opondo rigidamente quantitativo a qualitativo, explicação a compreensão ou extensividade a intensividade." (Pinto, 2007: 86)

De resto, a utilização de metodologias combinadas para obtenção de fundamentações analíticas mais consistentes, foi proposta num artigo de um dos primeiros números da Análise Social (em 1965), o que se haveria de repercutir no ensino da disciplina.

\footnotetext{
${ }_{13}$ A interpretação de António Teixeira Fernandes, no artigo sobre o "Conhecimento científico-social" (1996) a este respeito é também muito interessante.
} 
Quadro 3. Revistas Científicas de Difusão da Investigação Sociológica Portuguesa (N. ${ }^{\text {s }}$ publicados entre 2000-2007)

\begin{tabular}{|c|c|c|c|c|}
\hline \multirow[t]{2}{*}{$\begin{array}{c}\text { Centros } \\
\text { Investigação }\end{array}$} & \multirow[t]{2}{*}{ Revistas Científicas } & \multirow[t]{2}{*}{ Periodicidade } & \multicolumn{2}{|c|}{$\begin{array}{l}\quad N^{\circ} \mathbf{s} \\
\text { Publicados } \\
\text { (2000-2007) }\end{array}$} \\
\hline & & & N. ${ }^{\circ}$ & $\%$ \\
\hline ICS (Lisboa) & Análise Social (Desde 1962) & Trimestral & 31 & 17,1 \\
\hline IGIAS (Évora) & $\begin{array}{l}\text { Economia e Sociologia (Desde } \\
1965)\end{array}$ & Semestral & 14 & 7,7 \\
\hline $\begin{array}{l}\text { CES } \\
\text { (Coimbra) }\end{array}$ & $\begin{array}{l}\text { Revista Crítica de Ciências Sociais } \\
\text { (Desde 1975) }\end{array}$ & Quadrimestral & 21 & 11,6 \\
\hline CIES (Lisboa) & $\begin{array}{l}\text { Sociologia Problemas e Práticas } \\
\text { (Desde 1986) }\end{array}$ & Quadrimestral & 25 & 13,8 \\
\hline $\begin{array}{l}\text { CET } \\
\text { (Lisboa) }\end{array}$ & $\begin{array}{l}\text { Cidades. Comunidades e } \\
\text { Territórios } \\
\text { (Desde 2000) }\end{array}$ & Semestral & 14 & 7,7 \\
\hline $\begin{array}{l}\text { UNICS } \\
\text { (Lisboa) }\end{array}$ & $\begin{array}{l}\text { Portugal Journal of Social } \\
\text { Sciences (Desde 2002) }\end{array}$ & & 7 & 13,8 \\
\hline $\begin{array}{l}\text { Dep. De } \\
\text { Sociologia } \\
\text { (ISCTE / } \\
\text { Lisboa) }\end{array}$ & $\begin{array}{l}\text { Trajectos, } \\
\text { Revista de Comunicação, Educação } \\
\text { e Cultura (Desde 2002) }\end{array}$ & Semestral & 11 & 6,0 \\
\hline $\begin{array}{l}\text { CES-UA } \\
\text { (Açores) }\end{array}$ & $\begin{array}{l}\text { Revista Arquipélago - Ciências } \\
\text { Sociais }^{1}\end{array}$ & & & \\
\hline $\begin{array}{l}\text { Forúm } \\
\text { Sociológico } \\
\text { (Lisboa) }\end{array}$ & $\begin{array}{l}\text { Fórum Sociológico } \\
\text { (2. Série - desde 1999) }\end{array}$ & Semestral & 14 & $7,7 \%$ \\
\hline $\begin{array}{l}\text { CESEM } \\
\text { (Lisboa) }\end{array}$ & $\begin{array}{l}\text { Performance On-line - Revista de } \\
\text { Interpretação Musical (Desde 2005) }\end{array}$ & Anual & 2 & 1,1 \\
\hline $\begin{array}{l}\text { APSIOT } \\
\text { (Lisboa) }\end{array}$ & $\begin{array}{l}\text { Organizações e Trabalho (Desde } \\
\text { 1989) }\end{array}$ & Semestral & 8 & 4,4 \\
\hline Instituto de & Sociologia (Desde 1989) & Anual & 7 & 3,9 \\
\hline $\begin{array}{l}\text { Sociologia } \\
\text { (Porto) }\end{array}$ & $\begin{array}{l}\text { Cadernos de Ciências Sociais } \\
\text { (Desde 1984) }\end{array}$ & Quadrimestral & 5 & 2,8 \\
\hline $\begin{array}{l}\text { APM } \\
\text { (Lisboa) }\end{array}$ & $\begin{array}{l}\text { Revista Exaequo } \\
\text { (Desde 1999) }\end{array}$ & Semestral & 14 & 7,7 \\
\hline $\begin{array}{l}\text { CICS } \\
\text { (Minho/ }\end{array}$ & $\begin{array}{l}\text { Sociedade e Cultura, Cadernos do } \\
\text { Noroeste - Série Sociologia }{ }^{2} \text { (2000- } \\
2004)\end{array}$ & Anual & 6 & 3,3 \\
\hline Braga) & $\begin{array}{l}\text { Configurações, } \\
\text { Revista de Sociologia } \\
\text { (Desde 2005) } \\
\end{array}$ & Semestral & 2 & 1,1 \\
\hline TOTAL & 16 & & 181 & 100 \\
\hline
\end{tabular}

Fonte: Pesquisa efectuada através da Internet, entre 26.Dez.07 e 10.Jan.08. 


\section{Temáticas Recentes dos Centros de Investigação Sociológica e Abordagens sobre a Pobreza e a Exclusão Social}

\section{Uma Categorização Possível}

Uma das dimensões importantes analisada, foi a dos principais domínios de Produção Sociológica ${ }^{14}$ dos Centros de Investigação analisados, ou seja, categorizaram-se as linhas de pesquisa assumidas actualmente pelos centros, de acordo com alguns domínios de produção sociológica considerados, como se pode observar no quadro seguinte e que evidenciam as mais recentes tendências de pesquisa. Cada Centro possui mais do que uma linha de pesquisa (uma média de 4,5 por Centro) ${ }^{15}$, observando-se significativa diversidade em termos de problemáticas.

Propõem-se neste contexto três categorias de análise que se tentam situar no tempo, como dimensão meramente referencial:

- Domínios Clássicos, que surgiram essencialmente na época designada por Madureira Pinto de "novo fôlego" (basicamente dos anos 60 até aos anos de 1974) e que se mantêm hoje, com algumas reconfigurações.

- Domínios Consolidados, correspondendo basicamente a temas que surgiram a partir da institucionalização e consolidação da disciplina, de 1974 até aos anos de 1990.

- Domínios Emergentes, correspondentes a temas e problemáticas surgidas mais recentemente e, porventura mais ligados às solicitações externas, no âmbito quer da investigação-acção, quer de investigações aplicadas.

Constata-se então que os designados temas Clássicos, englobam problemáticas ligadas à "Estrutura e Mudança Social", que constituem temas de pesquisa importantes para $48 \%$ dos Centros aos quais se agregam temáticas actuais como a "Globalização e as Questões Europeias"16, enquanto a "Reflexão Epistemológica e Teórico-Metodológica" regista a adesão de $8 \%$ dos Centros, com problemáticas ligadas à "Juventude" e à "Educação" a serem explicitadas como domínios de pesquisa específicas por $4 \%$ dos Centros, em cada caso.

A propósito das linhas de pesquisa com peso significativo, importa sublinhar que datam de finais da década de 60 alguns estudos de fundo do GIS, justamente sobre a estrutura social portuguesa e o sistema de ensino universitário, já com sólida fundamentação teórica, epistemológica e metodológica e é interessante constatar que esta problemática continua a demonstrar relevo na actualidade.

No caso dos Domínios Consolidados encontram-se repartidos entre "Trabalho, Organizações e Profissões" (40\% dos Centros possuem linhas de pesquisa que trabalham este domínio), "Política e Estado" (36\% dos Centros explicitam linhas de pesquisa neste âmbito), "Cidade e Território" (em $28 \%$ dos Centros), seguem-se "Família e Género" (24\%), "Culturas" (20\%), "Pobreza e exclusão social" (12\%) e "Valores" (4\% apenas).

No que respeita aos Domínios Emergentes, destaca-se a linha de pesquisa sociológica ligada à temática das migrações, "Imigração e Etnicidade" (em 20\% dos Centros) e com menor expressão a "Ciência" e o "Ambiente" (8\% respectivamente) e, por último, a "Saúde" e as "Drogas e Toxicodependências" (4\% cada).

Foi ainda possível observar outros domínios que se constituem como os emergentes mais recentes, destacando-se com maior peso em $12 \%$ dos Centros, a "Sociedade do Conhecimento / TIC" e ainda, embora com valores relativos mais baixos, temáticas ligadas ao "Envelhecimento" e ao "Turismo", considerados respectivamente por $4 \%$ dos Centros de Investigação.

No entanto, importa referir que, em algumas situações são verificáveis "contaminações" entre linhas de pesquisa, ou seja, as problemáticas não são estanques, sendo por vezes muito difícil a sua categorização num domínio apenas.

\footnotetext{
${ }_{14}$ Esta dimensão de análise utiliza uma proposta de categorização possível, entre outras existentes.

15 Veja-se $o$ anexo com as principais linhas de pesquisa por Centro.

${ }^{16}$ Optou-se por agregar as temáticas "globalização e questões europeias" na da "estrutura e mudança social", ainda que elas sejam relativamente transversais já que emergem quer em textos de carácter teórico-reflexivos, quer em textos de abordagens comparadas (nomeadamente entre Portugal e a Europa) relativas à educação ou juventude

- temas clássicos, ou ainda à saúde ou imigração

- temas emergentes.
} 
Um denominador comum a boa parte dos centros é o facto de não se centrarem apenas em pesquisas fundamentais, respondendo também ao que se convencionou chamar investigação aplicada e avaliações de projectos e medidas de política.
Outra das funções importantes dos Centros consiste na possibilidade de experimentação da prática investigativa permitindo aos jovens investigadores um complemento na sua certificação e contribuem para a própria validação das suas competências, como bem referia António Firmino da Costa (1988).

Quadro 4. Domínios de Produção Sociológica Recentes, por Centro de Investigação, em Portugal

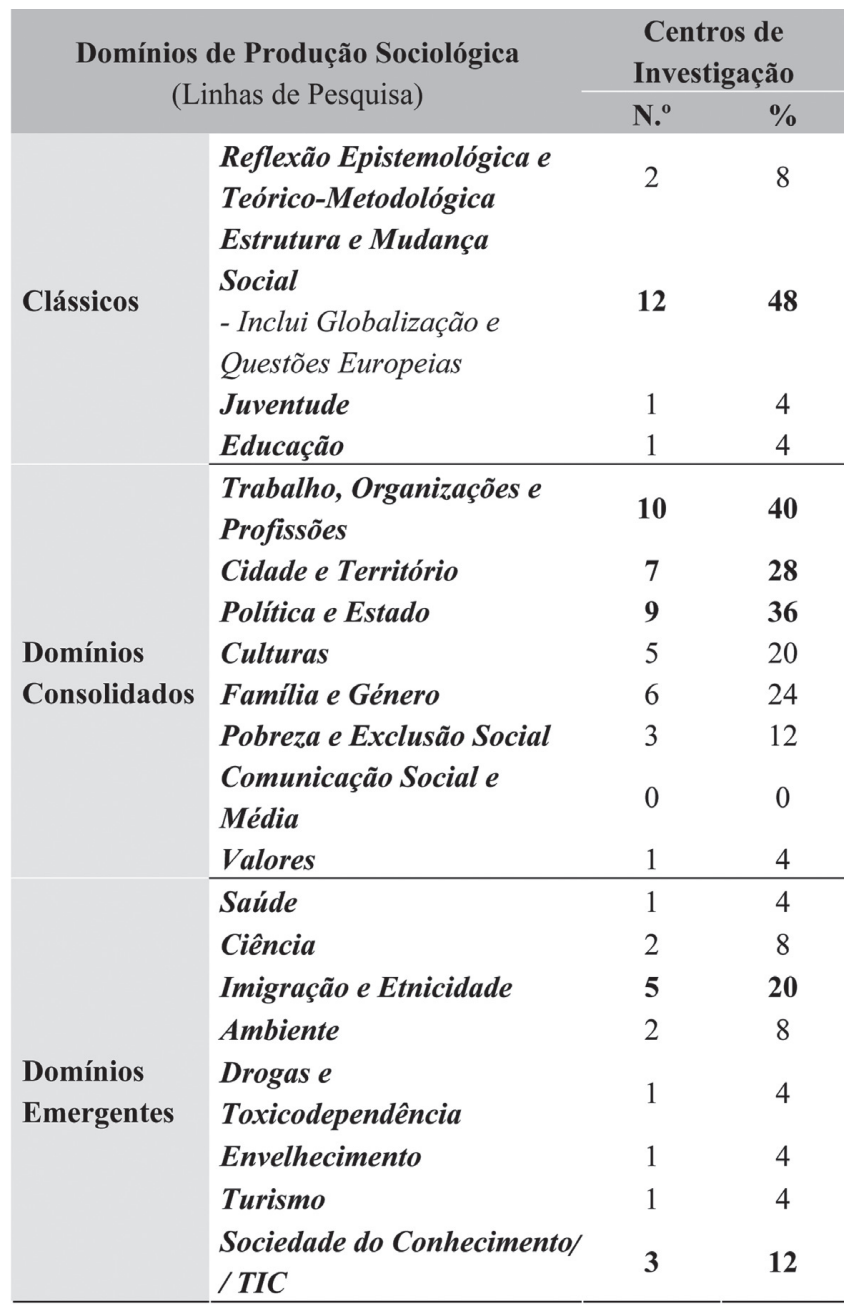

Neste âmbito, como nota referencial pode dizer-se que, relativamente aos domínios de produção sociológica, que em todas as Revistas publicadas (entre 2000-2007) foi possível encontrar artigos que respondem aos domínios categorizados em temas "clássicos", “domínios consolidados", “domínios emergentes" e outros mais extensivos até que os das linhas de pesquisa, embora com relevância variável.

Outros domínios não sociológicos também se revelaram presentes em boa parte das Revistas, nomeadamente nas que assumem na própria desig- nação como sendo de ciências sociais. Na verdade, nas respectivas páginas da Internet é possível, desde logo, observar uma referência a este alargamento do campo às ciências sociais e, não raras vezes, encontram-se artigos de pendor antropológico, económico, histórico e do direito, para referir apenas alguns exemplos.

Importa, contudo referir que muitas vezes é difícil operar categorizações, pois elas operam fracturas relativamente artificiais, uma vez que os domínios de cruzamento problemático são cada vez mais frequentes, assim como algumas demonstrações de interdisciplinaridade. 


\section{Abordagens Sobre a Pobreza e a Exclusão Social}

Foi ainda possível prestar alguma atenção às linhas de pesquisa sobre a problemática da pobreza e da exclusão social que parece marcar, de forma persistente e estrutural, a sociedade portuguesa.

A par com uma ideia de igualdade e integração/inclusão sociocultural, observam-se situações de exclusão económica, social, educativa, política (de cidadania), polarizando a sociedade.

São diversas as perspectivas de abordagem da inclusão identificadas, na medida em que esta se situa numa encruzilhada: a da multidimensionalidade das situações de pobreza e exclusão social e reclama uma proposta integrada, sistemática em termos de reflexão, análise e investigação sociológica, como suporte a políticas de intervenção, locais, regionais e nacionais.

Retomando os espaços de produção científica (os Centros), a pobreza e a exclusão social surgem como domínio consolidado, na categorização efectuada no quadro anterior e explicitada como linha de pesquisa em $12 \%$ dos Centros, como se referiu, nomeadamente através de projectos de investigação sobre "desigualdades e qualidade de vida" (CES-UA), "política e acção social - exclusão social" (CEOS, Univ. Nova) e sobre situações de "pobreza e exclusão social" que afectam "pessoas sem abrigo" e "crianças e jovens de meios desfavorecidos" (CESIS).

Este Centro promoveu, em 1999, um Seminário sobre Pobreza e Exclusão Social, Percursos e Perspectivas da Investigação em Portugal que contribuiu para efectuar um ponto de situação da investigação sobre esta problemática, em Portugal e no qual Manuela Silva assume que o primeiro artigo referenciado sobre este fenómeno, é da sua própria autoria, efectuado numa óptica económica - "Crescimento económico e pobreza em Portugal (1950-74)"17 e como assinala a autora, “(...) até então, a pobreza não era ainda tida como objecto de análise por parte dos meios académicos nacionais."
(Silva et al., 2000: p. 17) Este artigo teve, segundo a autora, um papel muito relevante no sentido em que permitiu tornar o fenómeno, bem como as suas proporções em Portugal, mais visíveis. Permitiu demonstrar ainda que apenas com base nos dados oficiais do INE não era possível um conhecimento aprofundado do fenómeno, nomeadamente as suas causas.

Nesta sequência, Alfredo Bruto da Costa deu conta de que o primeiro estudo compreensivo sobre esta temática - livro no qual é co-autor, designado A Pobreza em Portugal - data de $1985^{18}$. Este estudo foi efectuado com base num inquérito específico realizado a uma amostra representativa de 800 famílias consideradas pobres (isto é, consideradas, segundo os autores, como possuindo "níveis de rendimentos e/ou despesas abaixo dos limiares de pobreza"19), no decurso do mês de Fevereiro de 1985.

Por seu lado, em 1989, o livro sobre A Pobreza Urbana em Portugal, também coordenado por A. Bruto da Costa e Manuela Silva, é marcante do ponto de vista da integração da perspectiva sociológica nos estudos sobre a pobreza e a exclusão social. Assim, sociólogos integraram a equipa que efectuou esta pesquisa que incidiu sobre uma amostra representativa de pessoas residentes nos bairros degradados de Lisboa, Porto e Setúbal.

Em 1999, foram inventariados cerca de 205 títulos sobre esta temática ${ }^{20}$ (de diversas abordagens disciplinares), estando por efectuar um inventário até à actualidade, ainda que se tenha a percepção de que este número possa ter aumentado significativamente, nomeadamente por via de solicitações no âmbito da designada investigação aplicada.

Voltando às linhas de pesquisa actuais, uma análise mais aprofundada permite observar que este domínio consolidado, ganha conhecimento, reflexão e contributos por via de diversas linhas de pesquisa, como por exemplo, o da "cidade e território" (28\% dos Centros), através do "desen-

\footnotetext{
$\overline{17}$ Neste artigo, publicado em 1982, na Revista Análise Social Vol. XVIII, n. ${ }^{0 s} 72,73,74$, a autora trabalhou os dados do inquérito às receitas e despesas das famílias portuguesas, que haviam sido publicados pelo INE, notando que os instrumentos analíticos e de cálculo utilizados então eram ainda muito rudimentares.

18 Costa, Alfredo Bruto et al. (2000), "Sessão de Abertura”, In Actas do Seminário Pobreza e Exclusão Social, Percursos e Perspectivas da Investigação em Portugal, Lisboa, CESIS, Centro ISMAILI.

19 Idem, p. 18.

${ }^{20}$ Silva, Manuela; Rasgado, Sofia (1999), Pobreza e exclusão social na investigação em Portugal (1975-99) - Inventário Bibliográfico, Lisboa, CESIS.
} 
volvimento territorial" (UBI-CES), do aprofundamento do conhecimento sobre pessoas e grupos em situação de pobreza e exclusão, configurando necessidades e possibilidades de inserção, assim como através do empowerment, quer dos cidadãos, quer das organizações, incluindo empresas (em territórios de fortes assimetrias como os concelhos da Guarda e Seia, de Castelo Branco e Covilhã), ou dos obstáculos evidenciados no acesso às TIC e às regiões digitais.

Outra abordagem identificada surge por via de projectos de "Planeamento, gestão e desenvolvimento territorial" (notando-se um crescimento dos planos de âmbito social, do trabalho em parceria e da importância da governação, seja em contextos urbanos ou rurais); de projectos no âmbito das "Políticas sociais e urbanas de inclusão e igualdade de oportunidades", focalizados nos grupos sociais mais vulneráveis à pobreza e exclusão social e/ou no género e igualdade de oportunidades para as mulheres, nos imigrantes e minorias étnicas, nos mais jovens, e ainda no envelhecimento da população.

Nesta linha cabem ainda as políticas sociais e sua expressão territorial (nacional, regional e local), no âmbito da habitação, do emprego, da formação e da escolaridade. Refiram-se ainda as pesquisas sobre "Políticas de habitação e apropriação do habitat", centradas nas necessidades de habitação, satisfação residencial, habitação social e políticas de realojamento, requalificação urbanística de zonas degradadas ou de génese ilegal, modelos de apropriação do habitat, qualidade de vida e mudanças sociodemográficas (CET).

Também o Dinâmia se dedica à pesquisa no âmbito do "desenvolvimento do território e planeamento", nomeadamente sobre competitividade, coesão socioeconómica, planeamento e políticas de desenvolvimento regional/local; sobre competitividade, inovação e governança territorial (com particular enfoque nas actividades culturais); sobre processos de reestruturação nas áreas urbanas e metropolitanas e os seus impactes nas políticas regionais/locais em Portugal; e ainda sobre os processos de reestruturação económica das áreas rurais e os desafios às políticas de desenvolvimento rural em Portugal. Todas estas dimensões se repercutem ao nível da inclusão/ exclusão, quer territorial, quer socioeconómica.
Mas as perspectivas de inclusão são também transversais no âmbito de pelo menos uma das temáticas considerada nos domínios emergentes, a da "imigração e etnicidade", com linhas de pesquisa em cinco dos Centros em análise, evidenciando, desde logo, maior peso no SociNova Migrações, com contornos definidos na própria designação e cujas pesquisas se desenvolvem de acordo com as seguintes linhas de pesquisa: o impacto dos imigrantes nos sistemas demográficos; o turismo étnico: produção cultural e impactos urbanos; a participação cívica e inclusão política dos imigrantes; imigrantes e sociedade do conhecimento; colonialismo, pós-colonialismo e etnicidade; a construção da comunidade lusófona e fluxos transnacionais e identidades.

O ICS adoptou uma linha de pesquisa sobre identidade, migração e religião; o CESIS e o CET possuem estudos no âmbito dos migrantes e minorias étnicas e /ou culturais; o CES - Universidade dos Açores, enquadra alguns dos estudos no contexto das mobilidades, emigração e imigração e o SociNova efectua pesquisas sobre migrações, etnicidade e transnacionalismo.

Também as questões relativas às desigualdades, processos e recursos educativos (CEOS) ou os problemas relacionados com o desvio, a marginalidade, as drogas e toxicodependências (CEOS) são domínios geradores de contributos no âmbito do aprofundamento do conhecimento sociológico face à pobreza e exclusão social ou, no seu reverso, face à inclusão social.

Estes são apenas alguns dos exemplos que demonstram simultaneamente quer a grande diversidade de perspectivas de abordagem e de produção de conhecimento, quer a importância que esta problemática parece assumir no contexto da própria realidade social portuguesa.

Neste âmbito é ainda possível dar conta de alguns vazios, em termos de investigação sociológica, relativamente: a situações de extrema pobreza, como por exemplo, a das pessoas sem-abrigo (no âmbito dos Centros em referência apenas o CESIS possui algum trabalho sobre este grupo específico, no entanto, está ainda por fazer uma análise sociográfica que dê conta do quantitativo, dos perfis e da sua distribuição territorial; ao desemprego de jovens licenciados; à situação dos trabalhadores em precariedade laboral, portanto, dos trabalhadores pobres; à emergência de problemas de sobreendividamento e ao microcrédito, para referir apenas alguns exemplos. 


\section{Notas Finais}

No contexto deste breve ensaio, relembraram-se alguns aspectos relevantes da história da disciplina para a compreensão dos seus desenvolvimentos mais recentes. Optou-se por efectuar uma panorâmica sobre os principais centros de investigação nos quais se produz conhecimento sociológico (25, um dos quais sem actividades de investigação), analisando algumas dimensões que permitem contribuir para uma sociografia baseada: na territorialização, com um centramento muito forte em Lisboa e as principais linhas de investigação, assim como as Revistas de difusão do conhecimento e da cultura científica (16, duas das quais já sem publicação), analisando a sua evolução e expansão no tempo, a regularidade de publicação, verificando-se uma grande quantidade de $n .^{\text {os }}$ publicados entre 2000-2007 (181). Estas constituem apenas duas das faces institucionais da investigação sociológica.

No caso dos Centros observa-se uma expansão, que contribuiu quer para a visibilidade pública, quer para a institucionalização disciplinar, nos anos 80 e 90, enquanto as revistas registam expansão em anos mais recentes, observando-se que a mais antiga das revistas que publicam artigos de sociologia - a Análise Social (fundada em 1963) continua a manter um impressionante ritmo de publicação.

Optou-se também por analisar os principais domínios de produção sociológica dos Centros de Investigação, categorizando-se as linhas de pesquisa actuais, de acordo com alguns domínios de produção sociológica tendo-se tornado perceptível que cada Centro possui mais do que uma linha de pesquisa (uma média de $4,5 \%$ ).

Uma breve focalização sobre as abordagens relativas à pobreza e exclusão social, permitiu observar a transversalidade face a outros domínios de investigação e os principais marcos de referência da investigação sobre os fenómenos da pobreza e da exclusão social, em Portugal (na década de 1980).

A quantidade e diversidade de linhas de investigação observadas demonstram simultaneamente uma abrangência de estudos sobre a complexidade da realidade social e, de certo modo, em conexão com os problemas emergentes. Neste sentido, a internacionalização e os estudos em perspectiva comparada são também visíveis, assim como uma elevada preocupação em estudar as mudanças sociais.

As revistas constituem ainda espaços privilegiados para se obter uma panorâmica actualizada das produções científicas recentes, no entanto, em época de "globalização" e proliferação dos instrumentos informáticos, bem como de crescente acesso à Internet, observam-se ainda algumas dificuldades em aceder a determinadas páginas e são muito poucos os números recentes de revistas consultáveis on-line.

Devem ainda referir-se, de forma muito genérica, algumas das virtualidades atribuídas à Sociologia portuguesa que radicam desde logo nos primeiros anos de desenvolvimento e institucionalização que, embora tardia, permitiu aprofundar reflexões epistemológicas e metodológicas, superando algumas das dicotomias que noutros países se acentuavam; por outro lado, sempre lhe foi reconhecida uma vocação de interdisciplinaridade já que os primeiros autores que lhe consagraram atenção não eram sociólogos. Mais recentemente, isto é, na fase de institucionalização não se observou uma divisão entre os designados "profissionais" da sociologia e os "investigadores" em geral Professores Universitários (Machado, 2007).

Por seu lado, algumas das dificuldades que importa assinalar relacionam-se com a indefinição de políticas científicas que dêem a devida atenção à Sociologia; continua a verificar-se uma precarização do emprego científico, questão que, de certo modo, se relaciona com a primeira. Por outro lado, o emprego para profissionais de sociologia fora dos contextos universitários existe sobretudo através do sector público, nomeadamente a Administração central e local (Machado, 2007).

Esta breve pesquisa exploratória permitiu traçar algumas pistas para maior e mais sistemático aprofundamento, como a importância do conhecimento sobre os projectos realizados e em curso nos respectivos Centros, no sentido de melhor compreender a sua relação com a evolução e os processos de mudança da sociedade portuguesa. Mas também a necessidade de detectar o tipo de metodologias e técnicas adoptadas e traçar o perfil dos investigadores, sem esquecer a perspectiva de igualdade de género, quer no caso dos Centros, quer ao nível das revistas. 
Seria ainda interessante detectar, nomeadamente através dos artigos publicados não apenas as temáticas/problemáticas privilegiadas, mas também quer o peso da investigação proveniente do contexto universitário, quer de fora desse, pois parece haver indícios de um grande predomínio do primeiro face ao segundo, importando perceber porquê.

\section{Bibliografia}

ALMEIDA, João Ferreira de (2005), "Vinte anos da APS em Portugal", Sessão Comemorativa dos vinte anos da APS, 08.Setembro.2005, In www.aps.pt

ABRANTES, Pedro (2004), "Sociologia e Ciências da Educação, A distância entre nós”, Sociologia Problemas e Práticas, n. ${ }^{\circ} 45$, Celta Editora.

CESIS (2000), Actas do Seminário Pobreza e Exclusão Social, Percursos e Perspectivas da Investigação em Portugal, Lisboa, CESIS, Centro ISMAILI.

COSTA, António Firmino (1988), "Cultura Profissional dos Sociólogos", Sociologia Problemas e Práticas, n. ${ }^{\circ}$ 5, Pub. Europa-América.

FERNANDES, António Teixeira (1996), "O Conhecimento científico-Social em Portugal", Sociologia Problemas e Práticas, n. ${ }^{\circ} 20, \mathrm{CIES} / \mathrm{ISCTE}$.

MACHADO, Fernando Luis; CONDE, Idalina (1988), “A Divulgação Científica em Portugal", Sociologia Problemas e Práticas, n. ${ }^{\circ}$ 5, Pub. Europa-América.

MACHADO, Fernando Luis (1996), "Profissionalização dos sociólogos em Portugal: factores, recomposições e implicações", Sociologia Problemas e Práticas, n. ${ }^{\circ} 20$, CIES/ ISCTE.
Finalmente são ainda de assinalar algumas lacunas visíveis, em termos de investigação sociológica, nomeadamente no que respeita a situações de extrema pobreza, como a das pessoas sem-abrigo; situações de desemprego de jovens licenciados; situação dos trabalhadores em precariedade laboral, ou dos trabalhadores pobres; a emergência de problemas de sobreendividamento e ainda estudos no âmbito do microcrédito.

MACHADO, Fernando Luis (2007), A Investigação Sociológica em Portugal, Programa da Disciplina de Doutotramento em Sociologia, 2007-2008, 1. ${ }^{\circ}$ Ano, $1 .^{\circ}$ Semestre, ISCTE

SEDAS NUNES, A. (2000), Antología Sociológica (Selecção e Prefacio de Mónica, M. Filomena), ICS, Lisboa.

NUNES, João Arriscado (1998/1999), "Para além das “duas culturas': tecnociências, tecnoculturas e teoria crítica”, Revista Crítica de Ciências Sociais, Vinte anos de Teoria Social, n. ${ }^{\text {os }} 52 / 53$.

PINTO, José Madureira (2004), "Formação, Tendências Recentes e Perspectivas de Desenvolvimento da Sociologia em Portugal", Sociologia Problemas e Práticas, n. ${ }^{\circ} 46$, Celta Editora.

PINTO, José Madureira (2007), Indagação Científica, Aprendizagens Escolares, Reflexividade Social, Edições Afrontamento.

SILVA, Manuela; RASGADO, Sofia (1999), Pobreza e exclusão social na investigação em Portugal (1975-99) - Inventário Bibliográfico, Lisboa, CESIS.

TORRES, Anália (2005), "Vinte anos da APS em Portugal", Sessão Comemorativa dos vinte anos da APS, 08.Setembro.2005, In www.aps.pt 


\section{Web Sites:}

http://www.aps.pt

http://www.iscte.pt

http://www.apsiot.pt

http://www.apem-estudos.org/revista.html

http://www.ics.ul.pt

http://dinamia.iscte.pt/

http://www.ua.pt/

http://www.cies.pt

http://www.cet.iscte.pt

http://www.dinamia.iscte.pt

http://www-ext.lnec.pt/LNEC/DED/NESO/_private/index_ac-

tividade.htm http://socinova.fcsh.unl.pt/

http://cesnova.fcsh.unl.pt/

http://www.fcsh.unl.pt/forum/

http://ceos.fcsh.unl.pt/estatuto-org.asp

http://www.fcsh.unl.pt/revistas/forumsociologico.asp

http://www.apem-estudos.org/revista.html

http://www.ics.ul.pt/news/01/ICSNews01.pdf

http://www.ces.uc.pt/home.php

http://www.ces.ubi.pt/

http://www.fcsh.unl.pt/cesem/actividades/cesrelatorios.htm

http://www.performanceonline.org/pt/edicao_actual.html

\section{Anexos}

Anexo I - Territorialização dos Centros de Investigação Sociológica

\begin{tabular}{|c|c|c|c|c|c|c|c|c|c|c|c|c|c|c|c|c|}
\hline \multirow{3}{*}{$\begin{array}{l}\text { Tipos de Centros } \\
\text { de Investigação }\end{array}$} & \multicolumn{14}{|c|}{ Territorialização dos Centros de Investigação } & \multirow{2}{*}{\multicolumn{2}{|c|}{ Total }} \\
\hline & \multicolumn{2}{|c|}{ Açores } & \multicolumn{2}{|c|}{ Coimbra } & \multicolumn{2}{|c|}{ Covilhã } & \multicolumn{2}{|c|}{ Évora } & \multicolumn{2}{|c|}{ Lisboa } & \multicolumn{2}{|c|}{ Minho } & \multicolumn{2}{|c|}{ Porto } & & \\
\hline & N. ${ }^{\circ}$ & $\%$ & N. ${ }^{\circ}$ & $\%$ & N. ${ }^{\circ}$ & $\%$ & N. ${ }^{\circ}$ & $\%$ & N. ${ }^{\circ}$ & $\%$ & N. ${ }^{\circ}$ & $\%$ & N. ${ }^{\circ}$ & $\%$ & N. ${ }^{\circ}$ & $\%$ \\
\hline $\begin{array}{l}\text { Centros de } \\
\text { Investigação } \\
\text { Sociológica em } \\
\text { contexto } \\
\text { Universitário }\end{array}$ & 1 & 4,8 & 1 & 4,8 & 1 & 4,8 & 2 & 9,5 & 14 & 66,7 & 1 & 4,8 & 1 & 4,8 & 21 & 84,0 \\
\hline $\begin{array}{l}\text { Associações } \\
\text { particulares sem } \\
\text { fins lucrativos }\end{array}$ & & & & & & & & & 3 & 100 & & & & & 3 & 12,0 \\
\hline $\begin{array}{l}\text { Centros de } \\
\text { Investigação } \\
\text { Sociológica de } \\
\text { Entidades Públicas }\end{array}$ & & & & & & & & & 1 & 100 & & & & & 1 & 4,0 \\
\hline Total & 1 & 4,0 & 1 & 4,0 & 1 & 4,0 & 2 & 8,0 & 17 & 72,0 & 1 & 4,2 & 1 & 4,2 & 25 & 100 \\
\hline
\end{tabular}

Fonte: Pesquisa efectuada através da Internet, entre 26.Dez.07 e 10.Jan.08 


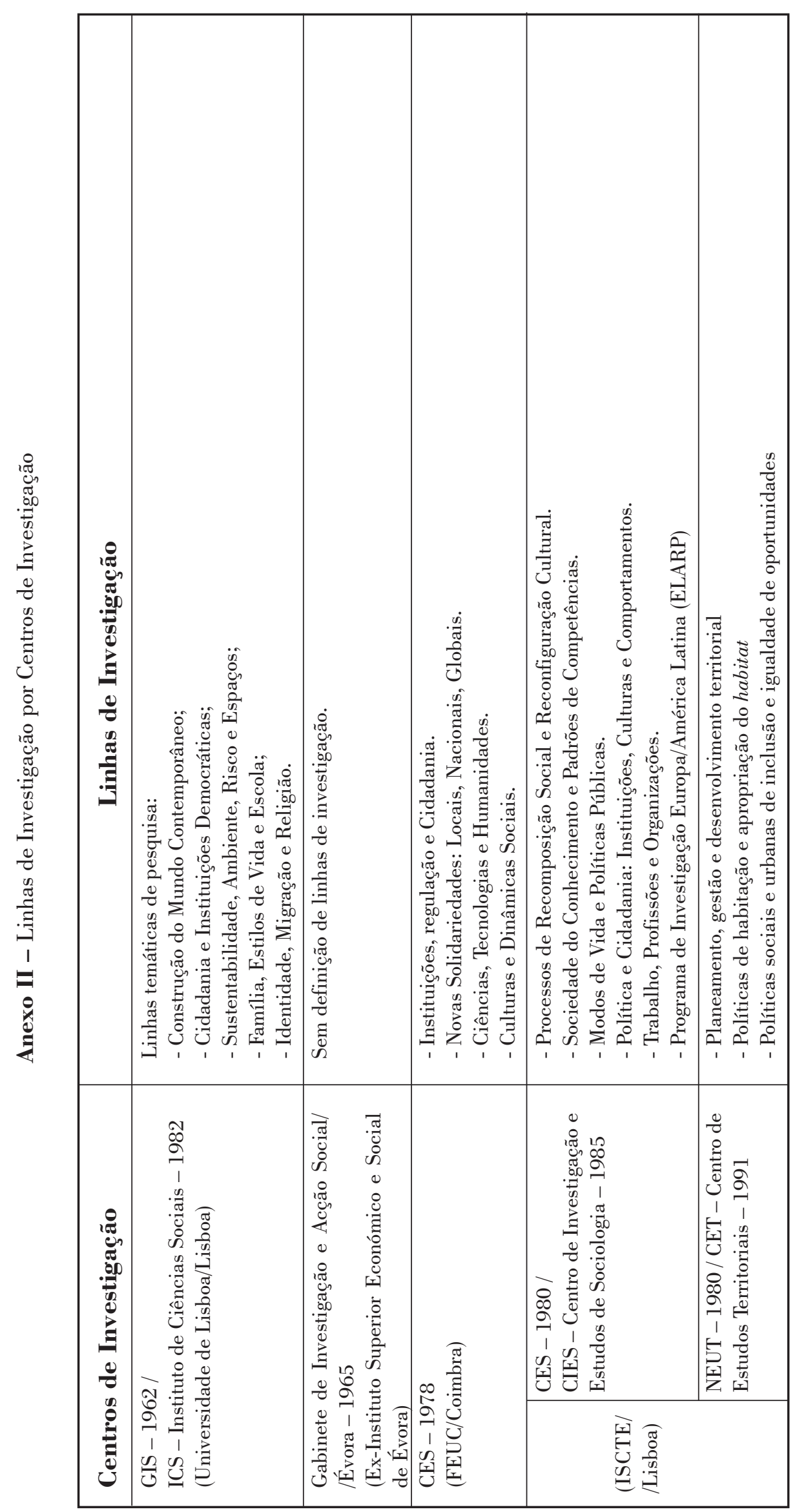




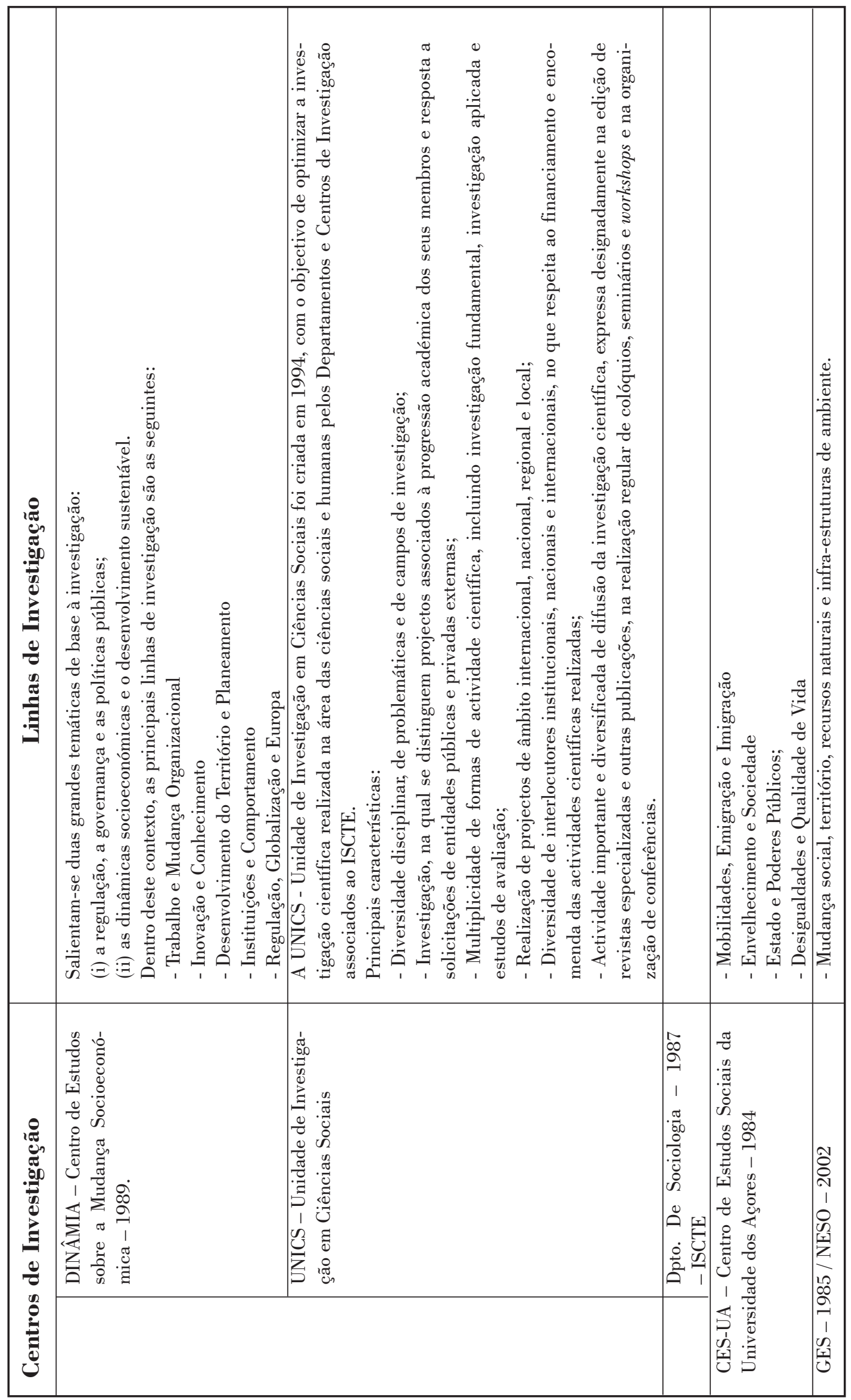




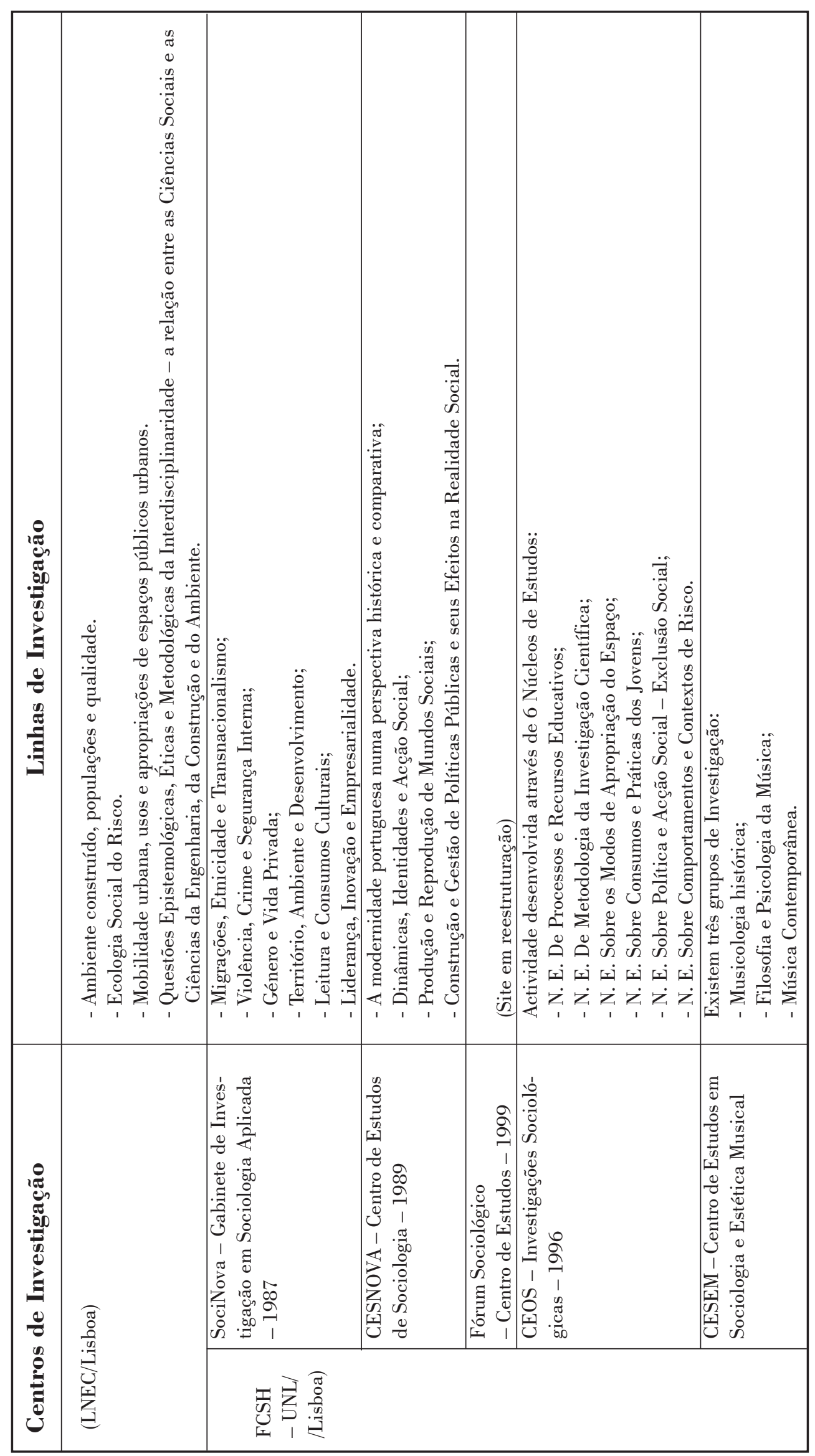




\begin{tabular}{|c|c|c|c|c|c|c|}
\hline 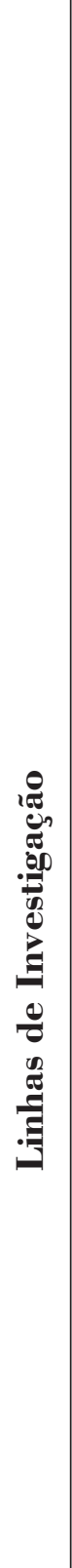 & 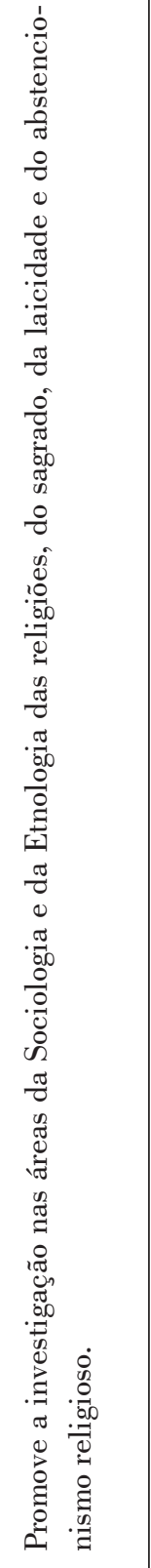 & 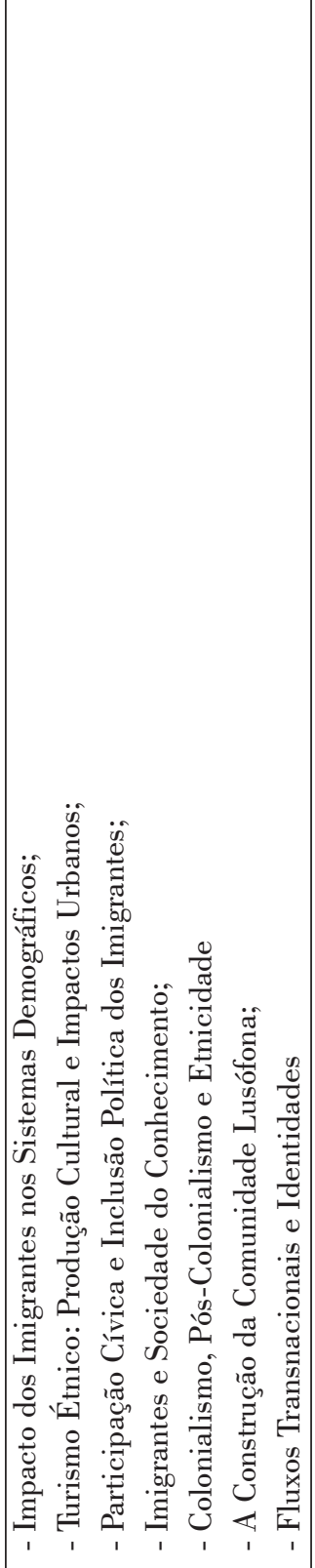 & 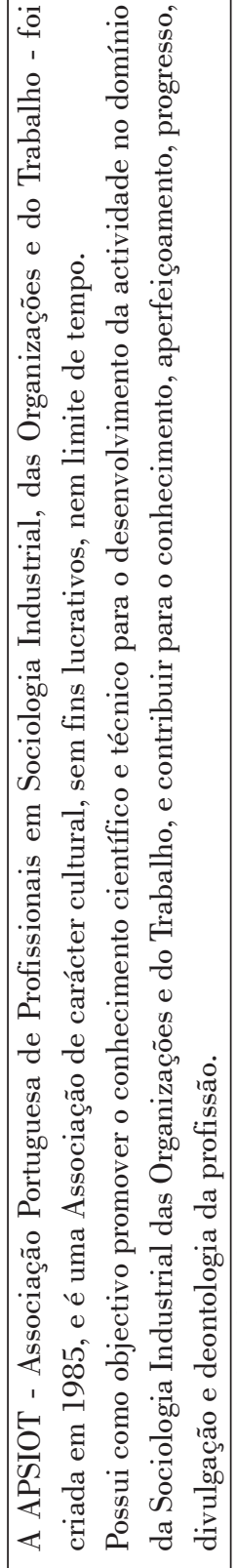 & 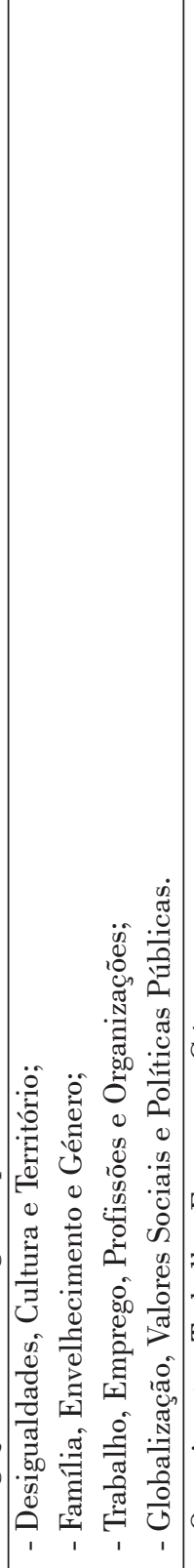 & 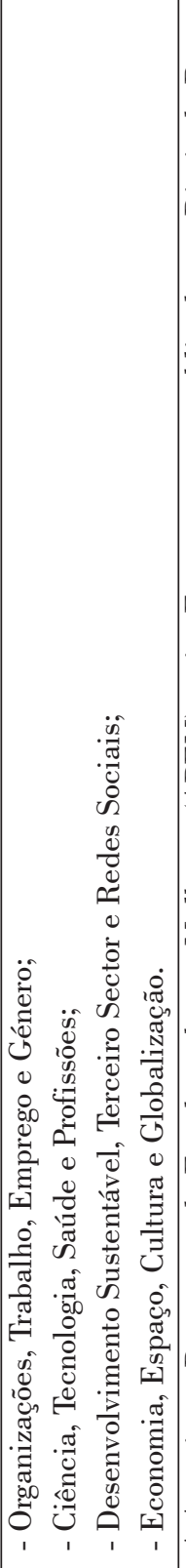 & 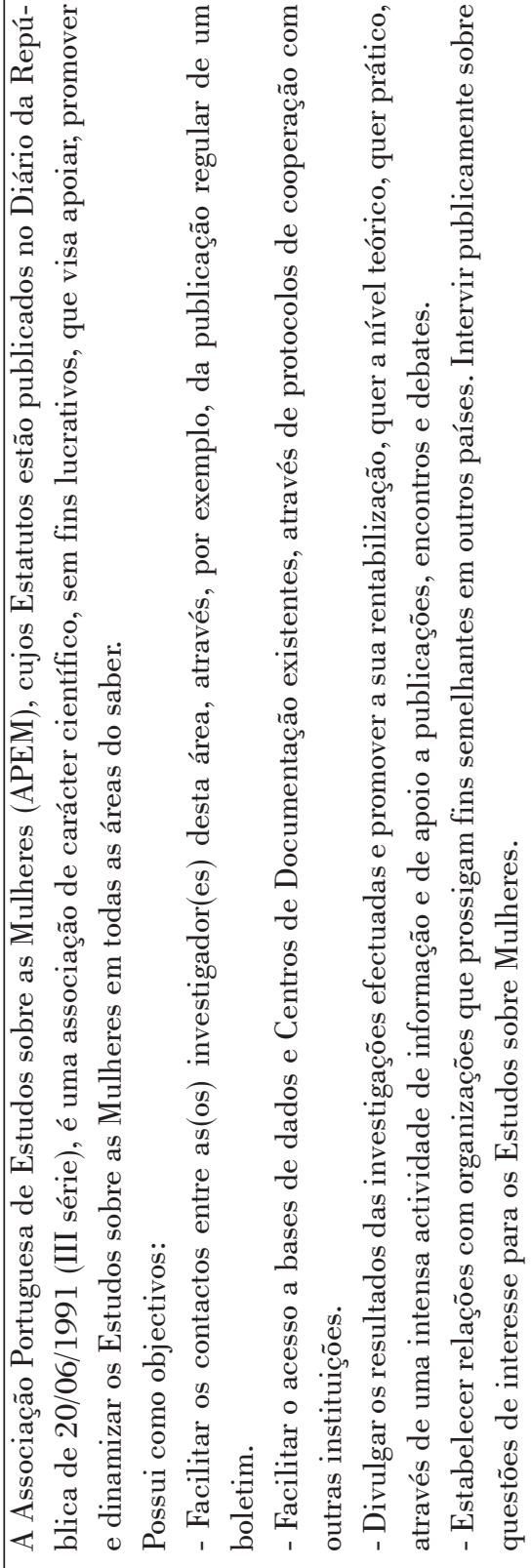 \\
\hline 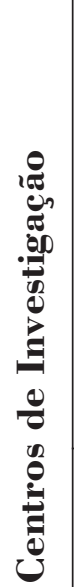 & 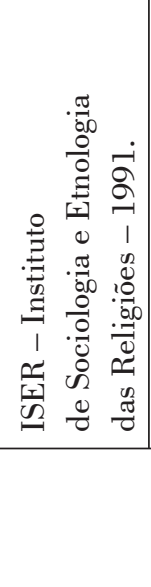 & 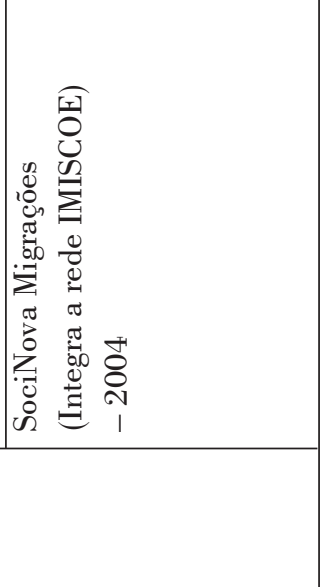 & 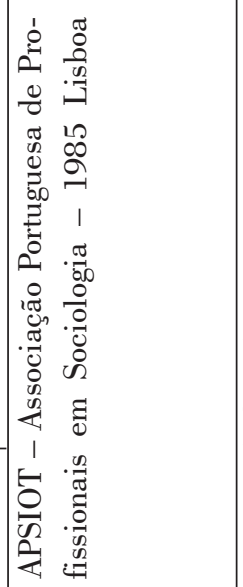 & 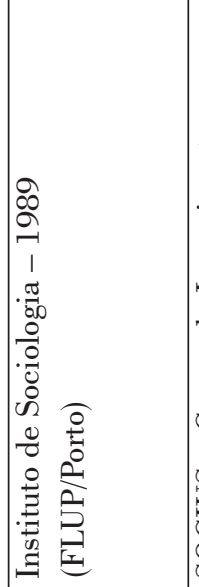 & 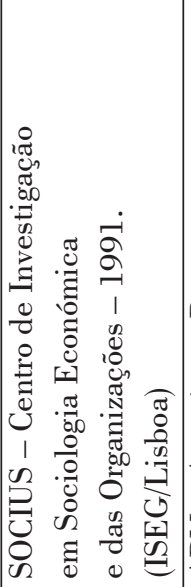 & 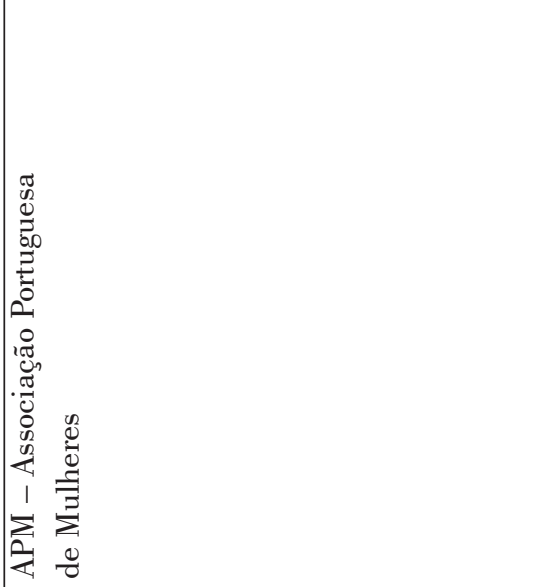 \\
\hline
\end{tabular}




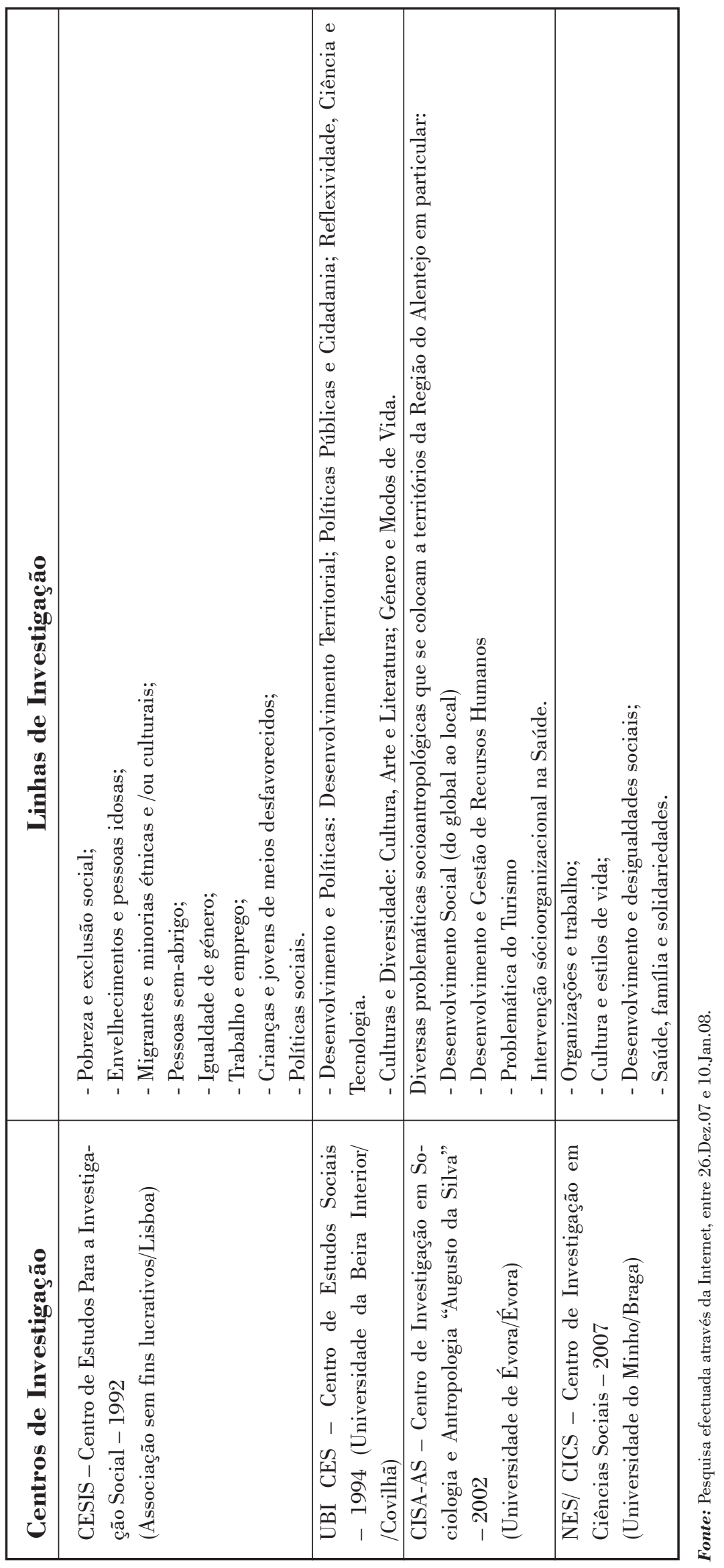

